\title{
SOFTWARE PARA MODELAGEM DE DISPERSÃO DE EFLUENTES EM RIOS
}

\section{SOFTWARE FOR MODELING EFFLUENT EMISSIONS IN RIVERS}

\section{RESUMO}

Este trabalho apresenta um modelo Fluidodinâmico Computacional tridimensional para simular a dispersão de substâncias solúveis em rios. $\mathrm{O}$ modelo pode predizer o impacto causado pela ocorrência de múltiplos pontos de emissão no trecho estudado. O código numérico para o modelo matemático foi desenvolvido em linguagem Fortran. Os resultados mostram que a metodologia proposta é uma boa ferramenta para a avaliação do impacto ambiental causado pela emissão de efluentes em rios. $\mathrm{O}$ software é bastante rápido, especialmente quando comparado com outros pacotes de CFD disponíveis comercialmente. Foram feitas comparações entre os resultados numéricos e dados experimentais coletados no rio Atibaia. Os resultados numéricos apresentaram uma boa concordância com os dados coletados experimentalmente.
\end{abstract}

MARCIO BEZERRA MACHADO

Engenheiro de Alimentos - Furg. Especialização em Engenharia Ambiental - Unicamp. Doutorado em Engenharia Química - Unicamp. Pesquisador da Faculdade de Engenharia Química da Unicamp

\section{LUIS TADEU FURLAN}

Engenheiro Químico - Unicamp. Mestrado em Engenharia Química - Unicamp. Doutorado em Processos de Separação de Isômeros por Adsorção - Università Politecnico di Milano. Gerente de Eficiência Energética da Petróleo Brasileiro S.A

\author{
MATEUS LAZARINI FURLAN \\ Estudante de Engenharia Elétrica - Unicamp
}

\section{EDSON TOMAZ}

Engenheiro Químico - Unicamp. Mestrado em Engenharia Química - Unicamp. Doutorado em Engenharia Química - Unicamp. Professor da Faculdade de Engenharia Química da Unicamp

\section{JOSE ROBERTO NUNHEZ}

Engenheiro Químico - Unicamp. Mestrado em Engenharia Química - Unicamp. Doutorado em Engenharia Química - Leeds University. Professor da Faculdade de Engenharia Química - Unicamp
PALAVRAS-CHAVE: Dispersão de efluentes, modelos matemáticos, fluidodinâmica computacional.

\section{INTRODUÇÃO}

No Brasil, os recursos naturais têm importância decisiva no plano econômico. O país é dotado de uma vasta e densa rede hidrográfica. A situação da poluição hídrica tem-se agravado no país, devido ao aumento das cargas poluidoras urbanas e industriais,

\begin{abstract}
This work presents a three-dimensional model for the dispersion of effluents in rivers using Computational Fluid Dynamics (CFD) techniques. There are several models in the literature, some of which even analyze complex flows. They are however restricted to small river sections. The main contribution of this work is that it proposes a new software capable of predicting the dispersion of effluents in very large open channels. The model is very fast, an unusual feature of CFD models. Due to this, it is possible to predict the dispersion of substances in long sections of rivers with some kilometers in extension. Moreover, multiple emissions can be analyzed by the model, allowing its use as a predictive tool to analyze and guide management decisions on future industrial installations near rivers. Results for the dispersion of an inert emission in a river near Campinas (Brazil) were used to validate the model.
\end{abstract}

KEYWORDS: Dispersion, mathematical models, computational fluid dynamics. na implantação de novas indústrias, especialmente quando for necessário o descarte de seus efluentes em rios. $\mathrm{Na}$ implantação de novos empreendimentos, para se obter a licença de instalação, embora em muitos casos seja elaborado um Estudo de Impacto Ambiental (EIA), a abordagem a respeito da previsão de impacto ambiental causado pela uso inadequado do solo e de insumos agrícolas, erosão, desmatamento e mineração. Estes fatores levam a danos dos recursos hídricos, dentre os quais se destacam o aumento do transporte de sedimentos e a contaminação orgânica e química das águas.

Esta situação crítica faz com que cuidados adicionais sejam tomados 
emissão de efluentes em rios tem sido pouco substanciada em metodologias científicas reconhecidamente aplicáveis para cada caso.

A legislação ambiental brasileira também vem se tornando cada vez mais restritiva. Neste contexto, convém citar a Resolução No 357 de março de 2005 do Conselho Nacional de Meio Ambiente (CONAMA) que dispõe sobre a classificação dos corpos de água e estabelece as condiçôes e padrôes de lançamento de efluentes. Nesta resolução, pode-se ler no artigo 33: " $A$ extensão $e$ as concentrações de substâncias na zona de mistura deverão ser objeto de estudo, nos termos determinados pelo órgão ambiental competente, às expensas do empreendedor responsável pelo lançamento". Sendo assim, todo empreendedor que venha a lançar efluentes em um corpo de água terá que realizar estudos semelhantes aos desenvolvidos neste trabalho.

$\mathrm{O}$ atual consenso sobre a preservação da qualidade da água de rios e lagos foi o motivador para a realização deste trabalho. Compreender o fluxo, a dispersão e a decomposição dos compostos presentes nos efluentes lançados em canais naturais é de extrema importância para a solução de vários problemas presentes no despejo de efluentes industriais nos rios. Entre estes problemas, destaca-se a escolha do melhor ponto de emissão de um efluente industrial, a determinação da distância necessária para a dispersão e mistura deste efluente e a distância para que ocorra a degradação das substâncias biodegradáveis presentes neste lançamento. Porém, o mais importante é desenvolver ferramentas numéricas preditivas do impacto causado por novas emissões de efluentes em um rio e por outras situações que ponham em risco o equilíbrio ambiental. Desta forma, um grupo de pesquisa foi formado visando o desenvolvimento de um modelo matemático determinístico, utilizando técnicas da fluidodinâmica computacional (CFD, do inglês Computational Fluid Dynamics).

Um modelo matemático tridimensional inédito foi gerado. $\mathrm{O}$ modelo tem um método de solução especialmente desenvolvido para este fenômeno, tornando-o muito mais rápido que os softwares comerciais de fluidodinâmica computacional disponíveis no mercado, como o Fluent e o CFX. O presente modelo é capaz de prever a dispersão de efluentes em trechos de rios com quilômetros de extensão em algumas horas. Os pacotes comerciais, por necessitarem de sofisticados métodos de resolução de sistemas matriciais, visto que são capazes de resolver problemas de escoamento de caráter geral, necessitariam de enormes clusters e de diversas semanas de trabalho para realizarem a mesma tarefa. É importante salientar que são incomuns na literatura acadêmica trabalhos com esta abordagem, visto que os modelos matemáticos publicados até o momento costumam ser unidimensionais ou bidimensionais, embora seja grande o interesse por parte de empresas e órgãos ambientais no desenvolvimento de instrumentos de previsão de impacto ambiental como o obtido.

No presente trabalho, o escoamento é considerado turbulento, característica da grande maioria dos rios. Para um melhor entendimento do comportamento do efluente no meio aquático, as reações de decomposição de substâncias não inertes também podem ser levadas em consideração. Além disso, é possível obter o perfil de concentração do oxigênio dissolvido ao longo de todo o trecho em estudo. $\mathrm{O}$ modelo também permite o estudo da dispersão de efluentes em trechos de rio onde exista mais de um ponto de lançamento. Esta ferramenta poderá ser aplicada em estudos para a predição da região de mistura devido a lançamentos de efluentes industriais e urbanos, estudos de toxicidade aquática com vistas ao atendimento à Resolução CONAMA 357/05, estudos de impacto de lançamento de efluentes para diversas classes de poluentes, conservativos ou não, como metais, matéria orgânica biodegradável, nutrientes, compostos orgânicos recalcitrantes, entre outros.

O modelo foi testado em diversos cenários durante trabalhos realizados em parcerias com indústrias da região. Os resultados numéricos apresentaram uma boa concordância com os dados experimentais obtidos. Outro detalhe importante deste projeto de pesquisa foi o desenvolvimento de uma nova metodologia para a obtenção do coeficiente convectivo de dispersão, fundamental para uma boa predição da dispersão de efluentes. A literatura sobre o assunto é escassa e a nova metodologia, baseada na coleta experimental do efluente tanto à montante quanto à jusante da emissão do efluente, se mostrou adequada para uma estimativa eficaz do coeficiente de dispersão.

\section{Modelagem matemática}

Foram desenvolvidas as equações diferenciais que descrevem o fenômeno. Estas equações são: a equação da continuidade, a equação da conservação de momento e a equação de transferência de massa de uma substância de interesse presente no efluente.

Para a solução destas equações, as seguintes hipóteses foram assumidas: regime turbulento; regime permanente; superfície plana, o que garante que a tensão seja nula na superfície; altura do leito constante; fluxo unidirecional e tridimensional; fluido newtoniano e propriedades físicas constantes, incluindo o coeficiente de dispersão que assume um valor constante médio, determinado experimentalmente. O leito do rio foi representado por meio de uma calha reta inclinada de base retangular. Esta geometria permite a simulação do fenômeno da dispersão de efluentes industriais em trechos de rios com largura e profundidade quaisquer.

Levando em consideração as hipóteses assumidas, obteve-se um sistema de equações diferenciais em coordenadas cartesianas que descrevem o escoamento em um canal de seção transversal retangular, conforme apresentado nas Equações 1 a 3 .

$$
\begin{aligned}
& \frac{2 v_{z}=0}{2 z} \\
& 0=\frac{2}{2 x} c\left(n+n_{T}\right) \frac{2 v_{z}}{2 x} m_{+} \\
& 1+\frac{2}{2 y} d\left(n+n_{T}\right) \frac{2 v_{z}}{2 y} n+\frac{t g H}{L} \\
& v_{z} \frac{2 C_{A}}{2 x}=\frac{2}{2 x} c K \frac{2 C_{A}}{2 x} m+ \\
& +\frac{2}{2 y} d K \frac{2 C_{A}}{2 y} n+R_{A}
\end{aligned}
$$

Em que $x$ é a coordenada cartesiana relativa à largura do rio, y é a coordenada cartesiana relativa à profundidade, $\mathrm{z}$ é a coordenada cartesiana do eixo longitudinal, $\mathrm{v}_{\mathrm{z}}$ é a velocidade do fluido na direção $z, \mu$ é a viscosidade laminar da água, $\mu_{\mathrm{T}}$ é a viscosidade turbulenta, $\rho$ é a massa específica, $g$ é a aceleração gravitacional, $\mathrm{H}$ é a cota de inclinação do rio, L é o comprimento do trecho do rio a ser estudado, $C_{A}$ é a concentração do efluente, $\mathrm{K}$ é o coeficiente de dispersão ou coeficiente global de transferência de massa, e $\mathrm{R}_{\mathrm{A}}$ é o termo de reação química.

A fim de se considerar os efeitos da viscosidade turbulenta, um modelo algébrico de ordem zero, proposto por Spalding (1961), foi usado. Este modelo 
é apresentado na Equação 4. De acordo com Spalding, esse modelo é capaz de representar adequadamente os dados experimentais de diversos escoamentos onde a viscosidade e a massa específica do fluido são constantes.

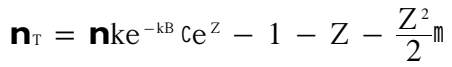

Em que:

$\mathrm{Z}=\frac{\mathrm{k}_{\mathrm{z}}}{\mathrm{v}^{*}}, \mathrm{k}=0,41$ e $\mathrm{B}=5,0$

Em que $\overline{\mathrm{V}}_{\mathrm{Z}}$ é a velocidade média do escoamento e ${ }^{*}$ é a velocidade de atrito.

Caso o poluente não seja biodegradável, o termo $\mathrm{R}_{\mathrm{A}}$ não é considerado, já que não há reaçôes químicas. Caso contrário, o termo $\mathrm{R}_{\mathrm{A}}$ deve ser considerado. Nesse caso, o perfil de concentração do poluente é obtido em função de sua Demanda Bioquímica de Oxigênio (DBO). A fim de predizer a distribuição espacial da DBO, o modelo de StreeterPhelps é utilizado. Este modelo considera os principais mecanismos existentes em rios recebendo matéria orgânica: a decomposição da matéria orgânica e a reaeração da água a partir do oxigênio atmosférico (Cox, 2003).

Nesse caso, a equação de transferência de massa deve ser resolvida duas vezes. Desta forma, são obtidos os perfis de concentração de DBO e de oxigênio dissolvido. $O$ termo $R_{A}$ na equação de transferência de massa que prediz a distribuição da DBO é um termo reacional de primeira ordem, como mostrado na Equação 6.

$\mathrm{R}_{\mathrm{A}}=\mathrm{v}_{\mathrm{z}} \frac{\mathrm{dC}_{\mathrm{DBO}}}{\mathrm{dz}}=-\mathrm{k}_{\mathrm{d}} \mathrm{C}_{\mathrm{DBO}}$

Já para obtenção da distribuição espacial da concentração de oxigênio dissolvido, o termo $\mathrm{R}_{\mathrm{A}}$ da equação de transferência de massa é substituído pela Equação 7.

$$
\begin{aligned}
& \mathrm{R}_{\mathrm{A}}=\mathrm{v}_{\mathrm{z}} \frac{\mathrm{dC} \text { Oxigenio }}{\mathrm{dz}}=-\mathrm{k}_{\mathrm{d}} \mathrm{C}_{\mathrm{DBO}}+ \\
& +\mathrm{k}_{\mathrm{a}} \mathcal{C}_{\mathrm{s}}-\mathrm{C}_{\text {Oxignio }} \mathrm{h}
\end{aligned}
$$

Em que $\mathrm{k}_{\mathrm{d}}$ é a constante de desoxigenação $\left(0,35 \mathrm{dia}^{-1}\right), \mathrm{k}_{\mathrm{a}}$ é a constante de reaeração da água $\left(1,0{ }^{\mathrm{a}} \mathrm{dia}^{-1}\right)$ e $\mathrm{C}_{\mathrm{S}}$ é a concentração de saturação de oxigênio dissolvido na água. Nas Equaçōes 6 e 7 , $\mathrm{C}_{\mathrm{DBO}}$ e $\mathrm{C}_{\text {Oxigênio }}$ são os valores obtidos na seção transversal anterior a calculada. A Equação 7 é dependente da Equação 6, já que o consumo de oxigênio é função da quantidade de matéria orgânica ainda presente na água.

As condiçôes de contorno para a equação de conservação de momento em z são a de não deslizamento na parede e a condição de tensão nula na superfície. Assim na parede: $\mathrm{v}_{\mathrm{z}}=0$; e na superfície: $2 \mathrm{v}_{z} / 2 \mathrm{y}=0$. As condiçōes inicial e de contorno para a equação de transferência de massa são a de concentração conhecida no início do domínio e a de fluxo de massa nulo na superfície e na parede. Esta última condição representa que não há acúmulo de massa nas paredes do rio e que não há transferência de massa do soluto para o ar. Esta consideração negligencia o fenômeno da evaporação da água. Como a dispersão de efluentes normalmente ocorre em trechos relativamente curtos (centenas de metros), a evaporação não tem nenhum efeito significativo e pode ser desconsiderada. Assim, no início do domínio tem-se: ; e nas paredes e na superfície: $2 \mathrm{C}_{\mathrm{A}} / 2 \mathrm{n}=0$, onde $2 / 2 \mathrm{n}$ representa a derivada na direção normal à superfície do domínio.

\section{METODOLOGIA DE SOLUÇÃO NUMERICA}

A solução do problema em estudo consiste basicamente em três etapas: a entrada dos dados, obtenção do perfil de velocidades e obtenção do perfil de concentração. Inicialmente deve-se fazer um levantamento das características do sistema. Dentre tais características estão as dimensōes do rio (largura, profundidade e comprimento); as vazôes do rio e do efluente; e a concentração do poluente, no rio e no efluente.

O perfil de velocidade é obtido através da resolução da Equação 2. Utilizando o perfil de velocidade, torna-se possível determinar a distribuição de concentração da substância no rio a partir da aproximação numérica da Equação 3. Para determinação do perfil de concentração de oxigênio dissolvido no rio, a Equação 3 também é utilizada.

O método dos volumes finitos foi utilizado e o problema foi resolvido de maneira parabólica, já que o perfil de concentração calculado em cada seção transversal do rio é função apenas da seção imediatamente anterior. Esta metodologia de solução reduz consideravelmente o esforço computacional e permite um maior refino da malha. Neste trabalho, foi utilizada uma malha com aproximadamente 44 bilhões de volumes de controle. O programa computacional foi desenvolvido em linguagem Fortran.

\section{RESULTADOS}

A seguir, será apresentada uma avaliação de impacto ambiental realizada com a utilização do modelo matemático. Neste estudo de caso, foi determinado o impacto ambiental causado pelo lançamento do efluente da empresa Rhodiaco, localizada em Paulínia-SP, às margens do rio Atibaia.

\section{Descrição do sistema de estudo}

Existe a foz do ribeirão Anhumas $450 \mathrm{~m}$ a montante do local de emissão do efluente da empresa. Esse ribeirão possui uma carga poluidora bastante elevada, uma vez que recebe o lançamento de esgotos domésticos da cidade de Campinas. O efluente da empresa tem uma vazão de $0,054 \mathrm{~m}^{3} / \mathrm{s}$. A vazão do rio Atibaia no dia da amostragem era de $10,8 \mathrm{~m}^{3} / \mathrm{s}$. Existem outros três pontos de emissão localizados ao longo do trecho estudado, denominados Caixa 008 (473 m à jusante da Caixa 005 e com vazão de $2320 \mathrm{~m}^{3} / \mathrm{h}$ ), Caixa 007 (540 m à jusante da Caixa 005 e com vazão de $1380 \mathrm{~m}^{3} / \mathrm{h}$ ) e Caixa 006 (635 m à jusante da Caixa 005 e com vazão de $310 \mathrm{~m}^{3} / \mathrm{h}$ ). Esses três pontos localizam-se na margem oposta à margem do lançamento do efluente.

No momento das amostragens foram realizadas medições da profundidade em 40 diferentes locais do rio Atibaia para obtenção da profundidade média. A partir dessas medições, obteve-se uma profundidade média de $2,1 \mathrm{~m}$ no momento da coleta das amostras. Foi definido também que a largura média do rio é de $27 \mathrm{~m}$. Esta largura média foi determinada por meio da análise de um levantamento topográfico realizado na região. É importante mencionar que o trecho de rio estudado é bastante irregular, apresentando diversas curvas em seu trajeto. Porém os resultados obtidos mostraram que o modelo matemático foi capaz de predizer satisfatoriamente o comportamento da dispersão do efluente.

\section{Método de estudo}

Esta fase do trabalho foi dividida em duas etapas: determinação do coeficiente de dispersão para o trecho de rio e simulação da dispersão do efluente no rio. 
A determinação do coeficiente de dispersão para o trecho de rio é dividida em três etapas: escolha do traçador; amostragem de campo e determinação do coeficiente de dispersão por ajuste do modelo aos resultados da amostragem.

O traçador escolhido para este estudo foi o sódio, pois, além de estar presente em uma concentração detectável com precisão no efluente, tem uma pequena concentração no rio Atibaia. Após ter sido escolhido o traçador, desenvolveu-se um plano de amostragem em que foram definidos diversos pontos de coleta de água em diferentes locais do rio. Analisou-se então a concentração de sódio em todas as amostras.

$\mathrm{Na}$ Figura 1 é mostrada uma representação do rio com a localização dos pontos ao longo de um trecho de 950 metros onde as amostras foram coletadas. Todas as distâncias lá representadas são em função da distância do ponto onde ocorre o despejo do efluente no rio. Estas distâncias foram: $10 \mathrm{~m}$, $30 \mathrm{~m}, 50 \mathrm{~m}, 70 \mathrm{~m}, 90 \mathrm{~m}, 150 \mathrm{~m}, 500 \mathrm{~m} \mathrm{e}$ $950 \mathrm{~m}$. Foram coletadas amostras também à montante do ponto de emissão de efluentes, a aproximadamente $50 \mathrm{~m}$ do local de emissão do efluente. $\mathrm{Na}$ Figura 1, os pontos de amostragem são representados por um número seguido por uma letra. Os pontos de amostragem representados pela letra A foram coletados a $3 \mathrm{~m}$ da margem onde ocorre o despejo do efluente; os representados pela letra $\mathrm{B}$ foram coletados a $7 \mathrm{~m}$; os representados pela letra C a $14 \mathrm{~m}$; e os representados pela letra $\mathrm{D}$ a $21 \mathrm{~m}$.

Todas as amostras foram coletadas diretamente na superfície do rio. Análises do teor de sódio foram realizadas também no efluente que estava sendo despejado no rio Atibaia (ponto E) e nos demais pontos de emissão oriundos de torres de refrigeração.

Uma vez obtidas as concentrações de sódio em diversos pontos do rio Atibaia, foi realizado o ajuste do modelo matemático desenvolvido. A partir deste ajuste, foi obtido um coeficiente global de dispersão característico para este trecho do rio. Foram testados diversos valores de coeficientes de dispersão e os resultados numéricos foram comparados com os dados experimentais. Para verificação de qual coeficiente melhor representava o fenômeno da dispersão, foi utilizado o método do somatório dos quadrados das diferenças dos resultados experimentais e numéricos.

Com a obtenção do coeficiente global de dispersão, torna-se possível realizar a simulação de todo o domínio considerado. Nesta simulação, o efluente foi considerado como tendo apenas um único componente. Esta abordagem é necessária para permitir a avaliação das condiçôes de mistura do efluente com as águas do rio Atibaia, como se este fosse um pseudo-elemento com as mesmas propriedades de transporte da água. Neste teste, o efluente é considerado na sua totalidade, com toda a sua complexidade, sem qualquer avaliação da sua composição. Este procedimento evita a necessidade de determinação da composição do efluente para determinar a sua toxicidade aquática, além de incorporar todos os efeitos sinergéticos e antagônicos entre os seus componentes que porventura possam aparecer. $\mathrm{O}$ fato do coeficiente de dispersão ter sido ajustado apenas para o sódio, e não para todo o efluente é minimizado devido à predominância dos efeitos convectivos em relação aos difusivos. Como no presente caso, também é utilizado um modelo turbulento, que é a caracterís- tica deste trecho de rio, considera-se suficiente a abordagem baseada na concentração do efluente no rio, como se fosse um pseudo-componente.

Após a determinação do coeficiente de dispersão característico e a validação do modelo para o trecho de rio estudado, o modelo encontra-se apto a predizer os perfis de concentrações para qualquer cenário, desde que respeitadas as hipóteses iniciais.

Para atender aos objetivos deste trabalho, empregou-se o modelo matemático e o código Fortran desenvolvidos para calcular os perfis de concentraçóes do efluente, correspondentes às seguintes simulaçōes: simulação da dispersão com as condiçôes do dia da amostragem de campo; e simulação da dispersão do efluente para o cenário do $Q_{7,10}$ (condição crítica de vazão, definida como a menor vazão ocorrida durante 7 dias consecutivos em um período de 10 anos).

\section{Resultados da determinação do coeficiente de dispersão}

Os resultados desta etapa do trabalho estão divididos em 3 partes: inicialmente é mostrado como foi obtido o coeficiente de dispersão característico para este trecho de rio; logo após é descrita a modelagem da dispersão do efluente nas condiçôes do dia da amostragem e, finalmente, é apresentada uma simulação da dispersão do efluente nas condições do $\mathrm{Q}_{7,10}$ do rio Atibaia.

Uma vez obtidos todos os parâmetros necessários, torna-se possível a realização de simulaçóes com o modelo matemático de diversas situaçōes a fim de se obter o coeficiente de dispersão que melhor ajuste o sistema estudado.

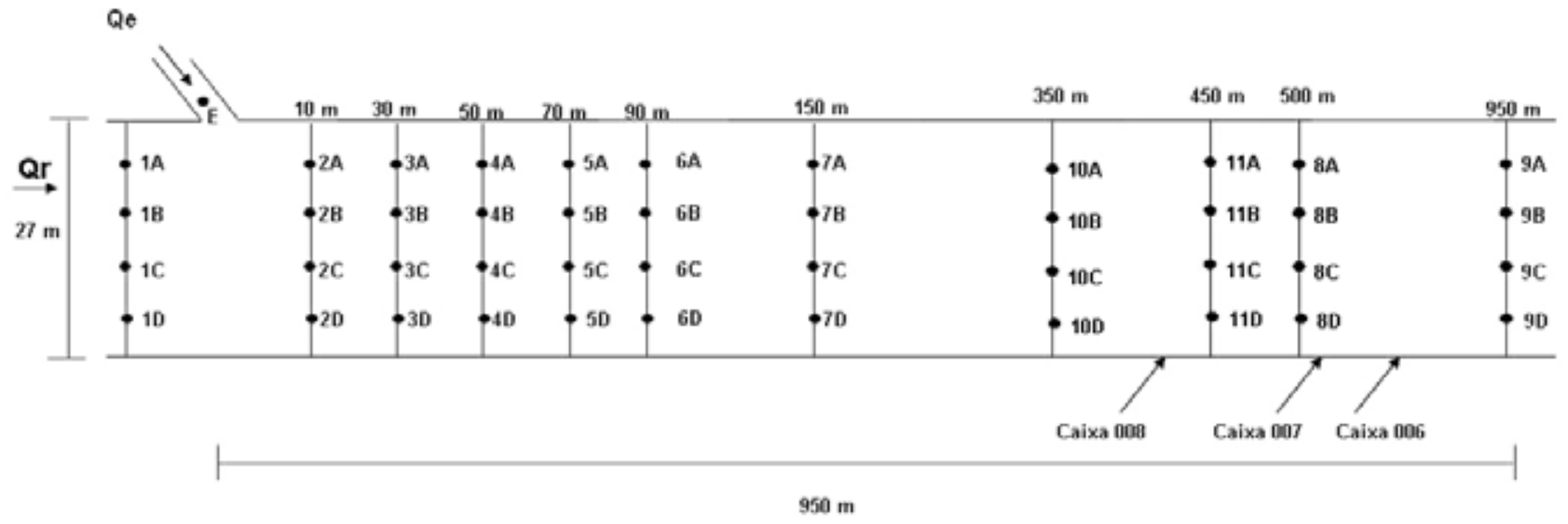

Figura I- Representação dos locais de coleta das amostras 
Foram testados diversos valores para o coeficiente de dispersão, variando de $0,005 \mathrm{~m}^{2} / \mathrm{s}$ até $0,19 \mathrm{~m}^{2} / \mathrm{s}$. Ao se comparar as curvas obtidas numericamente com os resultados experimentais, verificou-se que o coeficiente que melhor representava o fenômeno era o de $0,17 \mathrm{~m}^{2} / \mathrm{s}$. Desta forma, nas Figuras 2 a 5 são apresentadas apenas as curvas obtidas com esse coeficiente juntamente com os dados experimentais. Alguns pontos obtidos experimentalmente e que apresentaram comportamentos muito distantes do comportamento previsto pelo modelo foram desconsiderados. Porém, foram desconsiderados no máximo dois pontos experimentais para cada seção longitudinal estudada. Pode-se perceber que os resultados fornecidos pelo modelo representaram satisfatoriamente o comportamento do sistema, uma vez que ficaram bem próximos dos valores obtidos experimentalmente.

Após a determinação do coeficiente de dispersão que melhor representa o fenômeno estudado, tornou-se possível realizar a modelagem da dispersão do efluente. Como já foi descrito anteriormente, o efluente será modelado como se todos os seus componentes se comportassem da mesma maneira. Desta forma, obter-se-á um perfil de concentração do efluente na água do rio. Assim, todo efluente lançado terá concentração igual a 1,0 (100\%), e a água do rio terá uma concentração de efluente igual a zero (0 \%) a montante do lançamento.

Sabe-se que os componentes de um efluente não têm um comportamento semelhante, já que cada substância tem um coeficiente de dispersão característico. Porém, a realização da modelagem matemática desta maneira permite obter a determinação da porcentagem de efluente presente no escoamento ao longo de todo o trecho em estudo. $\mathrm{O}$ estudo deste caso considerou as vazôes e as dimensões medidas no dia da amostragem, conforme descritas anteriormente.

Foram determinadas as localizações das seções transversais em que as concentraçôes de efluente se reduzem a um máximo de $10 \%, 5 \%, 2 \%$ e $1 \%$ da concentração inicial. Estes resultados podem ser visualizados na Tabela 1 . Ao se observar os resultados mostrados nessa tabela, verifica-se que a dispersão do efluente ocorre em um pequeno trecho do rio. A uma distância de $31,21 \mathrm{~m}$, verifica-se que a porcentagem de efluente presente na água já é menor que $1 \%$ da sua concentração inicial.

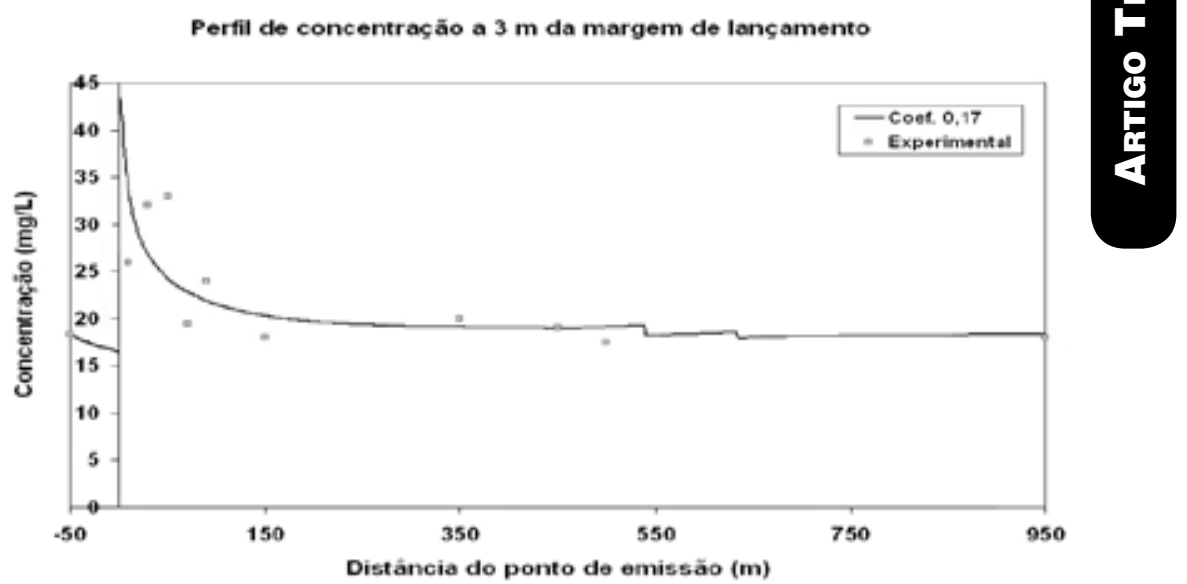

Figura 2 - Perfil de concentração de sódio em comparação com dados experimentais, a 3 m da margem

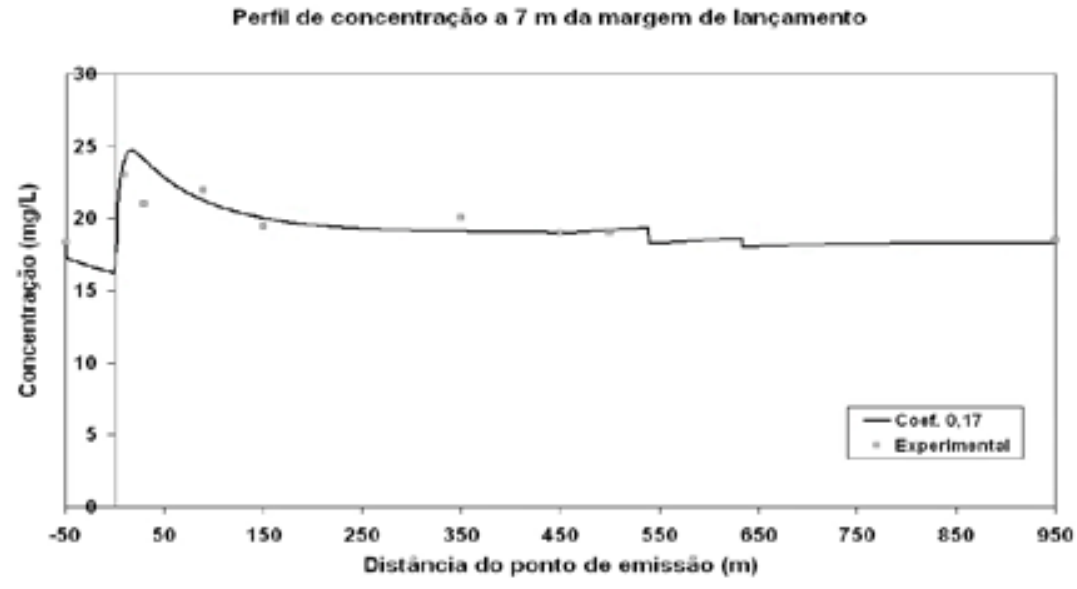

Figura 3 - Perfil de concentração de sódio em comparação com dados experimentais, a 7 m da margem

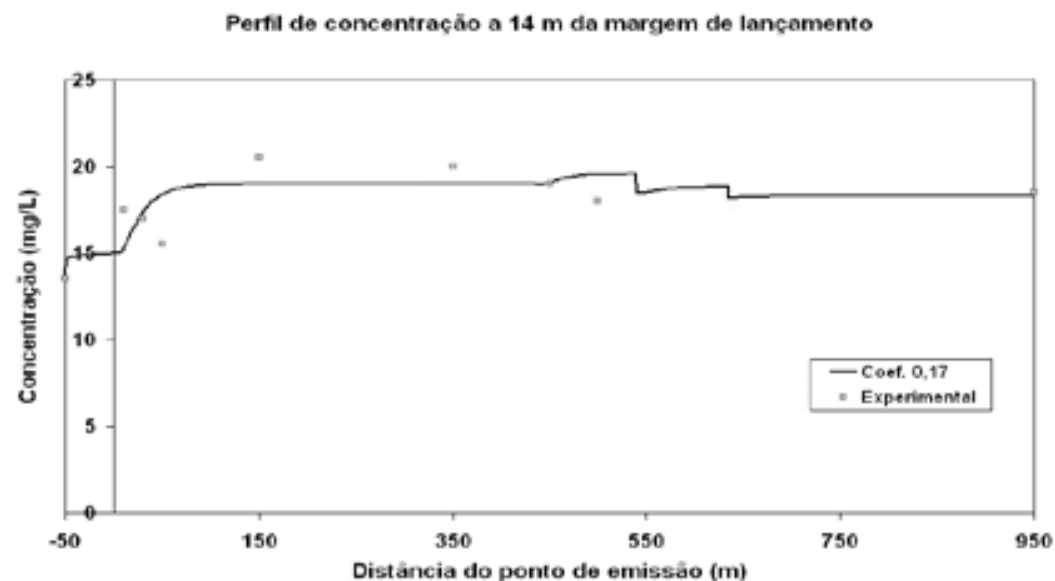

Figura 4 - Perfil de concentração de sódio em comparação com dados experimentais, a 14 m da margem 
Após a realização da modelagem matemática do perfil de concentração do efluente lançado nas condiçôes encontradas no dia da amostragem, realizou-se também uma simulação para as condiçôes críticas do sistema. Assim, considerou-se como vazão do rio Atibaia o seu $\mathrm{Q}_{7.10}\left(3,54 \mathrm{~m}^{3} / \mathrm{s}\right)$. Não há medições disponíveis das condiçôes do rio quando este se encontra com sua vazão mínima. Desta forma, considerou-se o pior cenário possível, ou seja, a largura do rio será considerada a mesma do dia da amostragem $(27 \mathrm{~m})$ e apenas a sua profundidade terá variação em função da vazão. Com essas consideraçôes, determinou-se que a profundidade média do rio em condições críticas é de 0,69 m. Esta relação entre profundidade e largura do rio é considerada o pior cenário possível, pois como o rio Atibaia é bem mais largo do que profundo, a dispersão do efluente na água do rio irá ocorrer de forma mais lenta no sentido de sua largura do que de sua profundidade. Assim, considerar que o rio Atibaia tem a mesma largura média em condições críticas de vazão que no dia da amostragem torna o estudo mais conservador, visto que o resultado fornecido pelo modelo será para o pior cenário possível (condições críticas de vazão em um rio largo e raso, onde o poluente terá que difundir até a outra margem para se considerar completamente disperso). O coeficiente de dispersão utilizado foi novamente de $0,17 \mathrm{~m}^{2} / \mathrm{s}$.

Foram determinadas as localizações das seções transversais em que as concentraçôes de efluente se reduzem a um máximo de $10 \%, 5 \%, 2 \%$ e $1,5 \%$ da concentração inicial. Estes resultados podem ser visualizados na Tabela 2. Como esta simulação tem o objetivo de simular o comportamento do efluente, não foram consideradas as emissões lançadas pelas caixas 008, 007 e 006.

A partir dos resultados mostrados na Tabela 2, verifica-se que nos primeiros metros após a emissão, ocorre uma dispersão mais rápida do efluente, sendo que a apenas $12,74 \mathrm{~m}$ do lançamento a porcentagem máxima de efluente na água é de $5 \%$. Após esta distância, devido à pequena vazão do rio, ocorre uma diminuição do gradiente de concentração. Desta forma, a dispersão ocorre mais lentamente. Na Figura 6 é mostrado o perfil de concentração do efluente na superfície do rio Atibaia

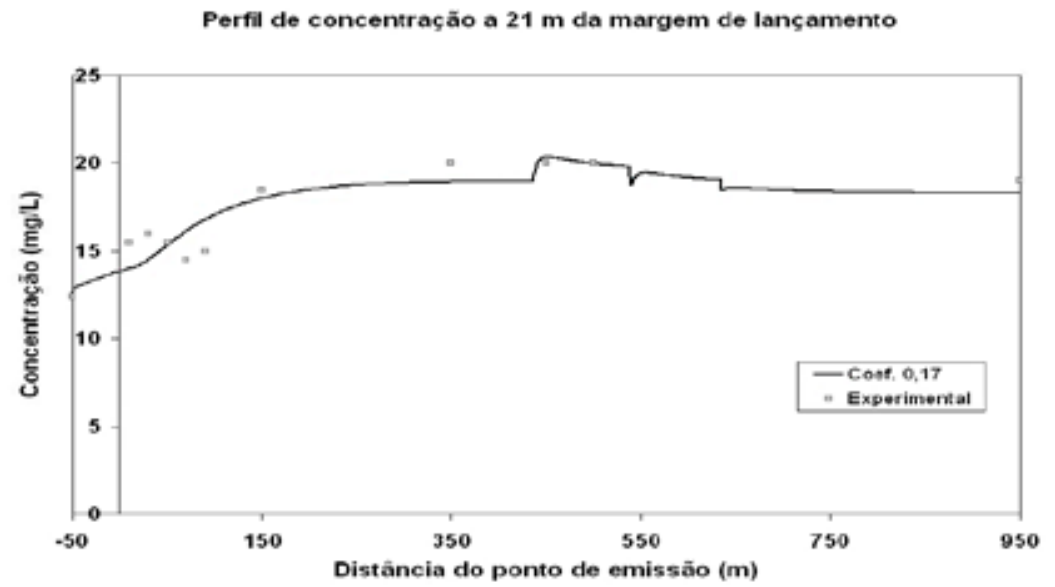

Figura 5 - Perfil de concentração de sódio em comparação com dados experimentais, a 2 I m da margem

Tabela I - Distâncias das seções transversais em relação a porcentagem de efluente na água do rio

\begin{tabular}{cc}
\hline $\begin{array}{c}\text { Máxima porcentagem de efluente na } \\
\text { seção transversal }\end{array}$ & $\begin{array}{c}\text { Distância do ponto } \\
\text { de emissão }(\mathrm{m})\end{array}$ \\
\hline $100 \%$ & 0 \\
$10 \%$ & 0,58 \\
$5 \%$ & 1,77 \\
$2 \%$ & 8,63 \\
$1 \%$ & 31,21 \\
\hline
\end{tabular}

Tabela 2 - Distâncias das seções transversais em relação a porcentagem de efluente na água do rio para ${ }_{\mathrm{Q}, 10}$

\begin{tabular}{cc}
\hline $\begin{array}{c}\text { Máxima porcentagem de efluente na } \\
\text { seção transversal }\end{array}$ & $\begin{array}{c}\text { Distância do ponto } \\
\text { de emissão }(\mathrm{m})\end{array}$ \\
\hline $100 \%$ & 0 \\
$10 \%$ & 3,16 \\
$5 \%$ & 12,74 \\
$2 \%$ & 79,60 \\
$1,5 \%$ & 143,80 \\
\hline
\end{tabular}

em condições críticas de vazão. Nesta figura, os resultados são apresentados em isolinhas de concentração. Essa forma de visualização é bastante útil quando se deseja comparar os resultados com índices de toxicidade do efluente. A partir do comportamento de uma determinada isolinha de concentração, torna-se possível determinar qual a área de influência crítica do efluente em estudo. Percebe-se que o modelo matemático descreveu o fenômeno de dispersão satisfatoriamente.

\section{CONCLUSÕES}

O presente trabalho apresenta uma ferramenta computacional inovadora, capaz de simular com fidelidade e rapidez a dispersão de efluentes em rios. O modelo desenvolvido é determinístico e tridimensional. É baseado na solução discreta das equações de conservação de massa e quantidade de movimento aplicadas a um trecho de rio com margem e profundidade constantes. A adequação do modelo a 


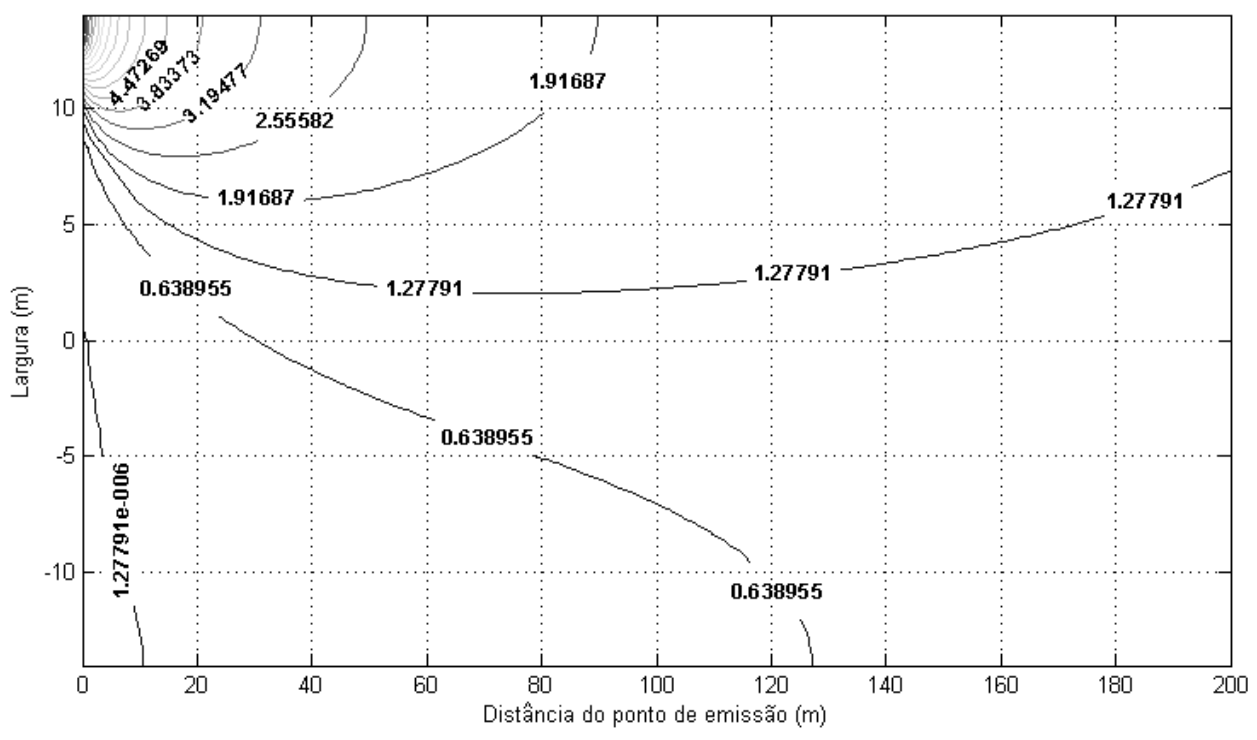

Figura 6 - Perfil de concentração em função das isolinhas de concentração do efluente

trechos de rios reais é feita por utilizar um comprimento e uma largura média do trecho de rio e dados experimentais de concentração de uma substância traçadora são utilizados para se encontrar o valor correto do coeficiente de dispersão do trecho de rio para este modelo. É importante salientar que não existe no mercado um software como o apresentado neste trabalho, incluindo o cuidado para se obter um valor correto para o coeficiente de dispersão do rio, evitando utilizar correlações empíricas aplicadas a rios do hemisfério Norte.

O modelo matemático desenvolvido tem totais condições de atender as exigências feitas pela Resolução CONAMA 357/05. Pode-se dizer que esse programa computacional poderá ser utilizado como uma importante ferramenta de suporte para a realização de estudos de impactos ambientais. Um software com interface gráfica para a plataforma Windows foi gerado a partir do modelo.

Os dados experimentais obtidos mostraram boa concordância com os resultados fornecidos pelo modelo, o que demonstra a grande aplicabilidade do modelo apresentado em estudos de impacto ambiental causado pela emissão de efluentes em rios. O software também pode ser utilizado para estimar o impacto de novas emissões em trechos de rios que já possuem uma quantidade significativa de emissões.

\section{AGRADECIMENTOS}

Os autores gostariam de agradecer à Replan / Petrobras pelo suporte financeiro ao projeto, à Fapesp pela bolsa de Doutorado Direto concedida ao trabalho (Processo 03/05869-3), à Rhodiaco pela liberação dos dados experimentais para publicação e à CETESB pelas valiosas críticas e sugestões feitas ao trabalho.

\section{REFERÊNCIAS}

COX, B. A. A review of currently available in-stream water-quality models and their applicability for simulating dissolved oxygen in lowland rivers. The Science of the Total Environment, v. 314-316, p. 335-377, 2003.

COX, B. A. A review of dissolved oxygen modeling techniques for lowland rivers. The Science of the Total Environment, v. 314-316, p. 303-334, 2003.

MACHADO, M. B. Modelagem Tridimensional da Dispersão de Poluentes em Rios. Tese (doutorado em Engenharia Química). Universidade Estadual de Campinas, UNICAMP, 147 f. Campinas, SP, 2006.

MODENESI, K. et al. A CFD model por pollutant dispersion in rivers. Brazilian Journal of Chemical Engineering, v. 21, n. 4, p. 557-568, out./dez., 2004.

RODI, W. Turbulence Models and their Application in Hydraulics. IAHR Monograph Series, $3^{\text {a }}$ Ediçẫo, 1993.

SPALDING, D.B. A single formula for the law of the wall. Journal of Applied Mechanics, v. 28, n. 3, Setembro, 1991.
Endereço para correspondência:

\author{
Márcio Bezerra Machado \\ Departamento de Processos \\ Químicos \\ Faculdade de Engenharia Química \\ UNICAMP \\ Av. Albert Einstein, 500 \\ Cidade Universitária Zeferino Vaz \\ Caixa Postal 6066 \\ I308 I-970 Campinas - SP - Brasil \\ Tel.: (19) 352 I-3967 \\ Email: machadomb@yahoo.com.br
}

